\title{
How resilient is the general population to heatwaves? A knowledge survey from the ENHANCE project in Brussels and Amsterdam
}

\author{
Joris Adriaan Frank van Loenhout ${ }^{*}$ and Debarati Guha-Sapir
}

\begin{abstract}
Background: Studies have shown an increase in mortality and morbidity during heatwaves, especially among the elderly. We assessed the knowledge of the general population of Brussels and Amsterdam on groups at risk and protective measures for heat-related health effects.

Results: Six locations with mixed populations were selected in each city. Passer-by's in both cities were asked to participate in a short survey. Respondents in Brussels $(n=120)$ had significantly more knowledge on risk groups and protective measures than respondents in Amsterdam $(n=133)$. In both cities, individuals with higher education had better knowledge on risk groups and protective measures than individuals with lower education.
\end{abstract}

Conclusions: Efforts at heat-awareness raising must be strengthened, especially in Amsterdam, and public health actions should effectively target vulnerable groups with lower education in both cities.

Keywords: Heat, Heat plan, Risk group, Protective measure, Awareness raising

\section{Findings \\ Background}

Exposure to heatwaves can lead to harmful effects in individuals. Globally, studies have shown an increase in mortality and morbidity among the elderly during heatwaves [1], and an increase in heat-related morbidity among small children [2], although other risk groups are also described (e.g. patients, socially isolated individuals). One of the most severe examples of a heatwave in Europe occurred in 2003, when over 15,000 individuals died in France alone [3]. Heatwaves are also set to increase in the coming years in Western Europe, both in frequency and intensity, due to climate change [4], threatening to aggravate the health situation of the community even further.

Following the 2003 heatwave, several European countries developed heatwave early warning systems or national heat plans [5]. These plans aim at reducing the

\footnotetext{
*Correspondence: joris.vanloenhout@uclouvain.be School of Public Health, Institute of Health and Society, Centre for Research on the Epidemiology of Disasters, Université catholique de Louvain, Clos Chapelle-aux-Champs 30, 1200 Woluwé-Saint-Lambert, Brussels, Belgium
}

avoidable human health consequences of heatwaves. Although the main purpose is to establish the role of professionals (e.g. in elderly care facilities, or general practitioners) during a heatwave, national heat plans also contribute in increasing awareness of heat risks in vulnerable groups and their care providers. The messages are channelled through community professionals and indirectly through the media.

Both Belgium and the Netherlands have a heat plan in place since 2005 and 2007, respectively [6, 7]. We assessed the knowledge of the general population of these countries on the groups at risk and protective measures for heat-related health effects, which provides an indication of the resilience of the population on this topic. Both heat plans address these issues, which should be generally known by the community, as most individuals either belong to a risk group or have one in their direct environment. Crucially as well, effective public health actions against heat are highly dependent on the popular perceptions that make up the health strategy, such as attitudes to heat, known protective measures and knowledge of 
risk groups. We hypothesised that there was no difference in knowledge level between the two cities.

\section{Methods}

This was a cross-sectional observational study, for which a two-page questionnaire was designed (Additional files 1,2). It included questions on demographics, the respondents' familiarity with the heat plan, risk groups for heat (open question) and protective measures against adverse heat-related health effects (open question). In addition, respondents were asked whether they considered themselves sensitive to extreme heat and whether the government was doing enough to raise awareness on this issue.

We selected Brussels and Amsterdam for our study, since they are the capitals and biggest cities of Belgium and the Netherlands, respectively, and the effects of heatwaves are stronger in urban areas due to the urban heat island effect. The study was conducted on 19-20 August 2015 within Brussels, and on 23-25 September 2015 within Amsterdam. Six locations with mixed populations in terms of socio-economic background were selected in each city. Different socio-economic indicators were available for both cities, namely average income per capita for Brussels and status score for Amsterdam (Table 1). Even though these indicators are not comparable between the two cities, they provide an indication of the variation in socio-economic diversity within each city. Passer-by's were asked to participate, and provided verbal consent. Interviews were conducted in Dutch, French and English. Individuals older than twelve years, living in Brussels or Amsterdam and speaking one of the survey languages were eligible for inclusion in the study. Tourists and workers not living in the city were excluded. Approximately 20 interviews were carried out per location.

Results from the questionnaire were compared between Brussels and Amsterdam, using Pearson Chi square tests and Independent Samples $t$ tests. A sensitivity analysis was conducted on the combined data using logistic regression, to assess whether educational level was associated with knowledge on risk groups and protective measures. This was done only for groups and measures where the familiarity was at least $10 \%$ (in one city or both). Another sensitivity analysis was carried out, to compare the proportion of elderly ( $\geq 65$ years of age) who named the elderly as a risk group to the proportion who considered themselves sensitive to heat. A p value of $<0.05$ was considered to be statistically significant, based on two-sided tests. Data were analysed using the software SPSS for Windows (version 22).

\section{Table 1 Description and indication of socio-economic status of locations per city where the survey was conducted}

\begin{tabular}{|c|c|c|c|}
\hline \multicolumn{4}{|l|}{ Brussels } \\
\hline Municipality & Survey location type & Average income per capitab & Ranking $^{\text {d }}$ \\
\hline Ixelles & Shopping street & $€ 15,068$ & 2nd quartile \\
\hline Etterbeek & Park & $€ 13,746$ & 3th quartile \\
\hline Etterbeek & Tram/bus connection & $€ 13,746$ & 3th quartile \\
\hline Brussels & Shopping street & $€ 12,079$ & 3th quartile \\
\hline Anderlecht & Outdoor market & $€ 11,356$ & 4th quartile \\
\hline Saint-Gilles & Tram/bus connection & $€ 11,718$ & 4th quartile \\
\hline \multicolumn{4}{|l|}{ Amsterdam } \\
\hline Area $^{a}$ & Survey location type & Status score ${ }^{c}$ & Ranking $^{d}$ \\
\hline Museumkwartier & Park & 2.62 & 1st quartile \\
\hline Landlust & Shopping centre & -0.66 & 4th quartile \\
\hline Apollobuurt & Shopping street & 2.88 & 1st quartile \\
\hline Oude Pijp & Outdoor market & 0.87 & 2nd quartile \\
\hline Bijlmer Oost & Shopping street & -2.2 & 4th quartile \\
\hline IJburg & Shopping street & 1.59 & 1st quartile \\
\hline \multicolumn{4}{|c|}{ a The Brussels Capital Region consists of 19 municipalities, while Amsterdam consists of 71 areas, all of them defined by unique zip codes } \\
\hline \multicolumn{4}{|c|}{$\begin{array}{l}\text { c The status score of each area, indicating the social status in comparison to other areas. This figure is a compilation of educational level, income and work situation of } \\
\text { the inhabitants, and was determined by the Social and Cultural Planning Agency of the Netherlands over the year 2014 [13] }\end{array}$} \\
\hline
\end{tabular}




\section{Results}

\section{Survey outcomes}

The samples were 120 and 133 for Brussels and Amsterdam, respectively, and there were no significant differences in gender, age and educational level (Table 2).

Knowledge on the heat plan did not significantly differ between the cities (Table 2), although 57\% of the respondents in Brussels familiar with the heat plan knew that it was last activated in 2015, compared to $28 \%$ in Amsterdam. Respondents in Brussels had significantly more knowledge on the elderly, children and socially isolated individuals as risk groups. Respondents in Amsterdam were more often not able to name any risk group, or named a group not formally considered as such (most often 'individuals with light skin'). Respondents in Brussels also had significantly more knowledge on drinking fluids, keeping the windows closed and visiting green areas as protective measures. Respondents in Amsterdam more often proposed 'using sunscreen' as an answer.

Respondents in Brussels considered themselves more sensitive for heat, and more often had the opinion that the government does not raise enough awareness on this topic (Table 2). Respondents in the Netherlands more often replied 'don't know' to the last question, mainly because they were simply not aware of any activities that the government takes with respect to heat.

\section{Sensitivity analyses}

Individuals with lower education had less knowledge of the elderly and children as risk groups, or named groups not formally considered at risk (Table 3 ). Individuals with higher education were significantly more aware of drinking fluids as a protective measure compared to those with medium or lower education. Also, individuals with higher education recognised more frequently the importance of avoiding heat/sun compared to those with lower education.

The proportion of elderly ( $\geq 65$ years of age) who named the elderly as a risk group for heat was $86.4 \%$. The proportion of elderly who considered themselves somewhat or very sensitive to heat was $63.6 \%$.

\section{Discussion}

Our study suggests that respondents in Brussels had greater knowledge on their national heat plan, and risk groups and protective measures for heat-related health
Table 2 Characteristics of respondents, their knowledge on risk groups and protective measures for heat-related health effects and their opinion on government activities

\begin{tabular}{|c|c|c|c|}
\hline & $\begin{array}{l}\text { Brussels } \\
N=120\end{array}$ & $\begin{array}{l}\text { Amsterdam } \\
N=133\end{array}$ & $\begin{array}{l}\text { Difference }^{a} \\
\text { p value }\end{array}$ \\
\hline \multicolumn{4}{|l|}{ Demographics of respondents } \\
\hline Male gender \% & 46.7 & 49.6 & 0.642 \\
\hline Average age in years (sd) & $45.5(18.1)$ & $43.5(19.6)$ & 0.399 \\
\hline Education $\%{ }^{b}$ & & & 0.515 \\
\hline Lower & 20.0 & 19.1 & \\
\hline Medium & 19.2 & 25.2 & \\
\hline Higher & 60.8 & 55.7 & \\
\hline \multicolumn{4}{|l|}{ Knowledge of respondents } \\
\hline $\begin{array}{l}\text { Familiarity with existence of the } \\
\text { heat plan } \%\end{array}$ & & & 0.314 \\
\hline Yes & 39.2 & 33.1 & \\
\hline No & 60.8 & 66.9 & \\
\hline \multicolumn{4}{|c|}{ Familiarity with risk groups for heat $\%^{c}$} \\
\hline Elderly & 87.5 & 69.2 & $<0.001$ \\
\hline Young children/babies & 64.2 & 43.6 & 0.001 \\
\hline Sick individuals/patients & 35.0 & 36.1 & 0.856 \\
\hline Socially isolated individuals & 9.2 & 0.0 & $<0.001$ \\
\hline Pregnant women & 4.2 & 3.8 & 0.868 \\
\hline Obese individuals & 2.5 & 6.8 & 0.111 \\
\hline $\begin{array}{l}\text { Individuals who perform a lot } \\
\text { of physical effort }\end{array}$ & 0.8 & 1.5 & 0.623 \\
\hline $\begin{array}{l}\text { Don't know/only non-formal } \\
\text { risk group }\end{array}$ & 10.0 & 24.8 & 0.002 \\
\hline \multicolumn{4}{|c|}{ Familiarity with protective measures for heat $\%^{c}$} \\
\hline Drink fluids & 80.8 & 59.4 & $<0.001$ \\
\hline Avoid heat/sun ${ }^{d}$ & 58.3 & 64.7 & 0.301 \\
\hline Adjust clothinge & 28.3 & 36.1 & 0.188 \\
\hline Cool the body ${ }^{f}$ & 22.5 & 18.8 & 0.467 \\
\hline Use fan or airconditioning & 18.3 & 24.8 & 0.212 \\
\hline Keep windows closed & 16.7 & 6.8 & 0.014 \\
\hline Avoid physical activity & 11.7 & 15.0 & 0.432 \\
\hline Adjust diet & 9.2 & 8.3 & 0.801 \\
\hline Visit green areas & 8.3 & 1.5 & 0.011 \\
\hline Use sunscreen & 6.7 & 25.6 & $<0.001$ \\
\hline Don't know & 1.7 & 0.0 & \\
\hline \multicolumn{4}{|l|}{ Opinion of respondents } \\
\hline Sensitive to heat \% & & & $<0.001$ \\
\hline Very much & 31.7 & 12.0 & \\
\hline Somewhat & 13.3 & 27.8 & \\
\hline Not at all & 54.2 & 59.4 & \\
\hline Don't know & 0.8 & 0.8 & \\
\hline
\end{tabular}


Table 2 continued

\begin{tabular}{llll}
\hline & $\begin{array}{l}\text { Brussels } \\
\mathbf{N = 1 2 0}\end{array}$ & $\begin{array}{l}\text { Amsterdam } \\
\mathbf{N = 1 3 3}\end{array}$ & $\begin{array}{l}\text { Difference }^{\mathbf{a}} \\
\text { p value }\end{array}$ \\
\hline $\begin{array}{l}\text { Sufficient awareness } \\
\text { by government \% }\end{array}$ & & & $<0.001$ \\
Too little & 46.7 & 28.6 & \\
Just enough & 38.3 & 31.6 & \\
Too much & 2.5 & 3.8 & \\
Don't know & 12.5 & 36.1 & \\
\hline
\end{tabular}

a Differences between groups were tested using an Independent Samples $t$ test for age, and Pearson Chi square tests in all other cases. Significant differences are in italics

b Educational level was categorised out of five groups in Brussels: (1) none, (2) primary school, (3) secondary school technical/professional (lower education), (4) secondary school general (medium education), (5) college/university (higher education); and seven groups in Amsterdam: (1) none, (2) primary school, (3) lower vocational education, (4) general secondary education (lower education), (5) secondary vocational education, (6) senior general or pre-university education (medium education), (7) college/university (higher education)

c Familiarity with risk groups and protective measures for heat-related health effects were asked as open questions, where respondents could provide as many answers as they wanted. Answers were later grouped in the abovementioned categories

d Avoid heat/sun includes the answers 'stay inside' and 'stay in the shade'

e Adjust clothing includes the answer 'wear a hat'

f Cool the body includes the answers 'swim' and 'take a shower'

effects than respondents in Amsterdam. Results from Amsterdam indicated some confusion between the terms 'exposure to heat' and 'exposure to sunlight'. Although the climates of the two cities are very similar, respondents in
Brussels considered themselves more sensitive to heat and felt that the government should be more proactive on public education.

Although heat-protection messages are fairly straightforward and are usually covered by the media before a heatwave happens [8], our results suggest that they do not effectively reach individuals with lower education. Current public health activities to raise awareness on heat should further strengthen their efforts to reach highrisk groups with lower education in both these countries.

Out of the elderly respondents, more than $20 \%$ were aware that the elderly are a risk group for heat, but did not consider themselves sensitive to heat. This implies that, even when the knowledge level of individuals is good, there can be a misperception of people's own risk.

Two other studies are relevant in the context of our study, both from the UK. First, a qualitative study among elderly persons indicated that most were able to provide appropriate examples of behaviours to reduce the effects of heat [9]. Second, a study concluded that education was positively correlated to heat-prevention action [10], confirming the findings of our study.

Our results are not necessarily representative for the cities of Brussels and Amsterdam, but they give a first indication of the knowledge and perception in these cities. There was a difference in weather circumstances between the two surveys (warm and sunny in Brussels, versus wet in Amsterdam) and in timing (the surveys were carried out 5 weeks apart), which might have had an

Table 3 The relationship between educational level of respondents and knowledge on risk groups and protective measures for heat-related health effects

\begin{tabular}{llc}
\hline & $\begin{array}{c}\text { Medium education } \\
\text { OR (95\% Cl) }\end{array}$ & $\begin{array}{c}\text { Lower education } \\
\text { OR (95\% Cl) }\end{array}$ \\
\hline Lower familiarity with risk groups for heat & & $3.1(1.5-6.5)$ \\
Elderly & $2.0(0.9-4.1)$ & $6.4(3.0-13.7)$ \\
Young children/babies & $1.9(1.0-3.5)$ & $1.5(0.7-3.0)$ \\
Sick individuals/patients & $0.9(0.5-1.7)$ & $0.4(0.2-0.8)$ \\
Don't know/only non-formal risk group & $0.7(0.3-1.7)$ & $2.0(1.0-4.0)$ \\
Lower familiarity with coping measures for heat & & $2.4(1.2-4.6)$ \\
Drink fluids & $2.2(1.1-4.3)$ & $2.0(0.9-4.2)$ \\
Avoid heat/sun & $0.9(0.5-1.8)$ & $0.9(0.4-2.0)$ \\
Adjust clothing & $1.3(0.7-2.5)$ & $0.8(0.4-1.6)$ \\
Cool the body & $1.2(0.6-2.7)$ & $1.4(0.5-3.9)$ \\
Use fan or airconditioning & $2.1(0.9-5.1)$ & $1.6(0.6-4.6)$ \\
Keep windows closed & $2.1(0.7-6.3)$ & $0.8(0.3-2.0)$ \\
Avoid physical activity & $1.6(0.6-4.1)$ & $0.5(0.2-1.1)$ \\
Use sunscreen & & \\
\hline
\end{tabular}

OR odds ratio, $\mathrm{Cl}$ confidence interval

a Differences between educational levels were tested using logistic regression, where 'higher education' was the reference group. Statistically significant ORs are in italics 
impact on the perception of individuals on heat, although we do not expect this to influence the individuals' knowledge level.

\section{Conclusions}

Our study results suggest that efforts at heat-awareness raising must be strengthened, especially in Amsterdam and perhaps in other cities of the Netherlands. We encourage a dialogue between representatives for the heat plans in Belgium and the Netherlands, to exchange their strategies on awareness raising with respect to heat in the population. Secondly, for both Brussels and Amsterdam, public health actions should effectively target vulnerable groups with lower education. This could possibly be better achieved by active collaboration between public health authorities and media that are popular among individuals with lower education, such as certain websites or news broadcasts. Lessons on how to involve communities can also be learnt from the Climate Vulnerability and Capacity Analysis Handbook, such as Participatory Learning for Actions (PLA) tools [11].

\section{Additional files}

Additional file 1. English version of questionnaire used in Brussels.

Additional file 2. English version of questionnaire used in Amsterdam.

\section{Authors' contributions}

JVL conceived the study, collected data, carried out the analyses and drafted the manuscript. DGS conceived the study and critically revised the article. Both authors read and approved the final manuscript.

\section{Acknowledgements}

We thank J. Gil Cuesta for her assistance in the field work and her suggestions on the manuscript, P. Wallemacq, E. Gerritse, and M. Vidotto for their assistance in the field work, and J. Rodriguez-Llanes for his input in the questionnaire and the analyses.

\section{Competing interests}

The authors declare that they have no competing interests.

\section{Availability of data and materials}

The data supporting the conclusions of this article are available upon request from the corresponding author.
Ethics approval and consent to participate

The IRB of the Université catholique de Louvain considered there were no ethical concerns for this study, since it is not a medical study and it does not fall within the scope of the Belgian Law of 2004. For the Netherlands, ethical review for a study using questionnaires is only required if the questionnaire either has a mental impact, requires travelling by participants or is filled out at multiple points in time, all of which was not the case in our study. All respondents provided verbal consent.

\section{Funding}

This study was funded by the European Commission through the ENHANCE project (Grant Agreement No. 308438).

Received: 11 December 2015 Accepted: 23 November 2016

Published online: 28 November 2016

\section{References}

1. Astrom DO, Forsberg B, Rocklov J. Heat wave impact on morbidity and mortality in the elderly population: a review of recent studies. Maturitas. 2011;69(2):99-105.

2. $\mathrm{Xu} Z$, et al. The impact of heat waves on children's health: a systematic review. Int J Biometeorol. 2014;58(2):239-47.

3. CRED. Centre for research on the epidemiology of disasters: the international disaster database-EM-DAT. 2015. http://www.emdat.be/. Accessed 1 July 2015

4. Parry ML, Canziani OF, Palutikof JP, van der Linden PJ, Hanson CE. Contribution of working group II to the fourth assessment report of the intergovernmental panel on climate change. 2007.

5. Lowe D, Ebi KL, Forsberg B. Heatwave early warning systems and adaptation advice to reduce human health consequences of heatwaves. Int J Environ Res Public Health. 2011;8(12):4623-48.

6. Hagens WI, van Bruggen M. Nationaal hitteplan. 2015.

7. Sante Publique, Securite de la Chaine Alimentaire et Environnement. Plan vague de chaleur et pics d'ozone. 2008.

8. Nationaal hitteplan dinsdag van kracht. 2015. http://www.nu.nl/binnenland/4077793/nationaal-hitteplan-dinsdag-van-kracht.html. Accessed 29 June 2015.

9. Abrahamson $V$, et al. Perceptions of heatwave risks to health: interviewbased study of older people in London and Norwich, UK. J Public Health. 2009;31(1):119-26.

10. Khare $\mathrm{S}$, et al. Heat protection behaviour in the UK: results of an online survey after the 2013 heatwave. BMC Public Health. 2015;15(1):878.

11. Daze A, Ambrose K, Ehrhart C. Climate vulnerability and capacity analysis handbook. Atlanta: Care International; 2009.

12. Statistics Belgium. http://statbel.fgov.be/en/statistics/figures/. Accessed 22 Aug 2016.

13. Sociaal en Cultureel Planbureau of the Netherlands. https://www.scp.nl/. Accessed 22 Aug 2016

Submit your next manuscript to BioMed Central and we will help you at every step:

- We accept pre-submission inquiries

- Our selector tool helps you to find the most relevant journal

- We provide round the clock customer support

- Convenient online submission

- Thorough peer review

- Inclusion in PubMed and all major indexing services

- Maximum visibility for your research

Submit your manuscript at www.biomedcentral.com/submit 